\title{
Some Insights into the Role of Social Media in Political Communication
}

\author{
Matthias Roth ${ }^{1}$, Georg Peters ${ }^{1,2}$ and Jan Seruga ${ }^{2}$ \\ ${ }^{1}$ Munich University of Applied Sciences, Department of Computer Science and Mathematics, Munich, Germany \\ ${ }^{2}$ Australian Catholic University, School of Arts and Sciences, North Sydney, Australia
}

\begin{abstract}
Keywords: Microblogging, Politics, Social Media, Twitter.
Abstract: Political communication in the social media network of Twitter has enjoyed a popularity increase in recent years. This also meant that the microblogging platform Twitter is now used in different countries for political campaigns as well as political discussions. For this study we collected data from more than 1,400 politicians in three countries Australia, Germany and the U.S. through the Twitter API. This data set with nearly one million tweets is the basis for our analyses, where we compare the behavior of the politicians on Twitter regarding differences and similarities in the political context. Amongst others we compare key figures concerning the year of joining, age groups, gender, user activity, and trend topics in the named parliaments. Thus we gain insight into the political communication on Twitter in the mentioned countries.
\end{abstract}

\section{INTRODUCTION}

Social media using Web 2.0 technology has emerged over the past few years as space for online communication. Meanwhile different services like Wikis, Blogs and Social Networks provide the opportunity for people to get together online. In addition it is possible to consume content and also publish your own content. Furthermore, social media caused a change in the traditional structure of mass communication in the political context. Besides newspapers, magazines and TV channels a lot of political communication now goes through these Social Media Platforms. These allow a straight forward communication between politicians and citizens who are interested in politics.

Based on the U.S. Congress, the development of political participation in social media can be traced. It was observed that more than $65 \%$ of members of the U.S. Congress had established a personal web site by 1997 (Adler, 1998). Also in 2005 it was investigated that nearly all members of the U.S. Congress had developed web sites (Esterling et al., 2005). In the near past, February 2009, two months after the 2008 election 69 Congress members (which was a share of about $13 \%$ of the U.S. Congress) maintained a Twitter account (Golbeck et al., 2010). Just after the 2012 election the share was about $91 \%$. These increased figures show that the political communication in the U.S. has evolved in the direction of social media.

With interfaces that allow people to follow the lives of friends, acquaintances, and families, the number of people on social networks has grown exponentially in recent years. Facebook, Twitter and LinkedIn, to give a few examples, contain hundreds of millions of members, who use these networks for keeping track of each other. In 2004, Mark Zuckerberg created Facebook as a way to connect with fellow students. Now, in October of 2012 Facebook has about one billion monthly active users (Facebook, 2012).

Another example: Twitter, launched in July 2006, is an online social networking and microblogging service that has about 500 million accounts (Semiocast, 2012). Also LinkedIn is a social networking web site for people in professional occupations and was launched in 2003. With more than 180 million members in over 200 countries LinkedIn is the largest professional network in the world (Morphy, 2012). According to the user base of these three platforms also the site visits rose sharply. Alexa, a company that tracks web traffic, ranked Facebook, Twitter and LinkedIn as three of the most visited sites in the world. Currently, Facebook is in this ranking on position two just behind Google. The web sites Twitter and LinkedIn follow with the rankings of eight and thirteen (Alexa, 2012). This shows that social media is more and more spread.

In this paper, we contribute to the research field of social media in politics by examining the relevance of Twitter in political communication by the exposi- 
tion of Twitter activities in politics for three different countries. More specifically, we explore the activity of using social media in general and compare the single parliaments of Australia, Germany and the U.S. regarding activity, contribution in online political communication and further statistical figures.

Based on our findings, we derive implications, regarding politics in the named countries. Additionally, we provide a section related work for the fields of political science and social media.

This paper is structured as follows. The next section provides related work on political science and social media. Also you can find information about the methodology and research questions in section two. Furthermore, in our main part we present our research findings in sections three and four. The paper ends with an conclusion and gives an outlook for future research.

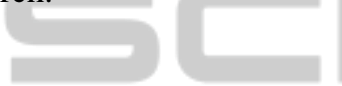

\section{RELATED WORK AND METHODOLOGY}

Twitter is a digital realtime Application for the distribution of short messages. It is also described as a communication platform for social networking or as a public online log. Private persons, enterprises, mass media and also politicians use the platform for distribution of short messages. On this basis we provide in this section related work about political science and social media and especially Twitter. In addition to the related work this section contains a description about the used methodology.

\subsection{RELATED WORK}

There has been some prior work on analysing social media. As a basis for further investigations there are works about social networks like the book by Wasserman and Faust, which describes different models, methods and applications for analysing social networks (Wasserman and Faust, 1994). Also much research is available about social science topics, which focus on the subjects of measuring performance of individuals and collectives to networks of social relationships. Backstrom, for example investigated group formations like membership, growth and evolution in large scale networks (Backstrom et al., 2006).

In terms of political communication Golbeck et al. present in their study a framework for viewing or understanding the content of Congressional communication through the capturing and categorizing of individual messages (Golbeck et al., 2010). Java et al. identified different types of user intentions and studied community structures also with respect to politics (Java et al., 2007).

In this elaboration, the focus is on Australia, Germany and the U.S. For these three countries initial studies have already been conducted with regards to political discussion on Twitter. For example Missingham looked at the Australian parliament in the Twitterverse (Missingham, 2010). Missingham found in her 2010 study that the Australian parliament was exploring the use of Twitter and about $15 \%$ of the Australian parliament members had a Twitter account.

For the German parliament Tumasjan tried to investigate in an analysis of the 2009 election whether Twitter is used as a platform for political communication and in addition whether Twitter can be seen as a valid mirror for offline political sentiment (Tumasjan et al., 2010). Regarding the U.S. Smith shows, how Barack Obama has used social media in the 2008 election campaign and the following use of social media in political campaigns in the U.S. (Smith, 2011).

\subsection{Methodology}

This paper aims to understand how members of a parliament communicate through Twitter. When and how often they tweet, how many followers and friends they have and how often their tweets are being retweeted. In addition to the named figures, a comparison between the parliaments of Australia, Germany and the U.S. is made. Thereby the focus is on the flow of communication from the government to the public. For example all the tweets and followers of various politicians will be examined but not the comments and communication from public to the government. As such, we have collected and analysed information about Twitter accounts and single posts. In this section, we will describe the data collection and research questions.

\subsubsection{Data Collection}

First of all, information about the Members of the Parliaments like forename, surname, age, party affiliation and Twitter account names were obtained by the corresponding web sites of the Australian, German and U.S. parliament. Thus we have acquired data for different houses. Our data consisted of a Senate and a House of Representatives each for Australia and the U.S., whereas for Germany, we used the comparable Bundestag and Bundesrat.

In Table 1, we show the different houses for Australia, Germany and the U.S. together with the corresponding seats. The House of Representatives is also called the Lower House or Bundestag in Germany and 
represents the people. The Senate or Upper House in Germany is called Bundesrat and is established for representing the single states of a country.

Therefore, difference between the Senate and House of Representatives is less conceived as representation of the total number of the states people, as more than representation of the states at the federal level. For easy intelligibility we will speak about parliaments and parliament members or parliamentarians for all three countries.

Table 1: Houses and seats of the parliaments.

\begin{tabular}{|l|l|r|l|}
\hline & Australia & Germany & U.S. \\
\hline $\begin{array}{l}\text { Lower } \\
\text { House }\end{array}$ & $\begin{array}{l}\text { House of } \\
\text { Represen- } \\
\text { tatives }\end{array}$ & Bundestag & $\begin{array}{l}\text { House of } \\
\text { Represen- } \\
\text { tatives }\end{array}$ \\
\hline Seats & 150 & 620 & 435 \\
\hline $\begin{array}{l}\text { Upper } \\
\text { House }\end{array}$ & Senate & Bundesrat & Senate \\
\hline Seats & 76 & 69 & 100 \\
\hline
\end{tabular}

For subsequent collection of Twitter data a Java application was developed which makes use of the Twitter Application Programming Interface (API) (Twitter, 2012). Over this interface information like Twitter account data and tweets can be accessed. Through the development of further analysis capabilities for our application we could gain more information from the downloaded data. Among others we have developed functions to identify trending topics, calculate the activity status and get the quantity of mentions of an account in the corresponding parliament. All these information serve as the database for research.

- Users. We only have added accounts to our data set for which a profile picture existed, because only then real interest for social media is identified. Furthermore there are a lot of fake accounts for politicians. There are currently more than 20 fake accounts for the former Australian Prime Minister Kevin Rudd.

Some of the fake accounts clearly labeled as fakes and some are not so easy to recognize as fakes. Most easily this can be handled by Twitter verified accounts, but not many politicians have verified accounts.

So we found the proper accounts by visiting politicians web sites. It is further pointed out that many accounts are not maintained by the politicians themselves, but by their staff. In our study we have all accounts treated the same, whether led by a politician themself or even led by their team.

- Active Users. We have added all the politicians and fetched their data, but the variable indicating whether each Member of the Parliament has created a Twitter account is not convincing. Not all Members of the Parliament continue using their Twitter account after creating it. For example, 109 Australian (48\%), 283 German (41\%) and 489 member of the U.S. parliament $(91 \%)$ created already a Twitter account, but overall there are still 13 accounts with not a single tweet. Therefore, we use an additional measure named active user in an effort to account for these differences. Here we determine that an active user has on average two or more tweets per week posted.

As shown in Table 2 this results in 74 Australian, 168 German and 393 active users in the U.S. The table furthermore shows the indicators regarding tweets, followers and friends for our data set divided into three countries of investigation. These three indicators relate to the total number of accounts, not just the active users.

Table 2: Indicators of the data set.

\begin{tabular}{|l|r|r|r|}
\hline & Australia & Germany & U.S. \\
\hline Members & 226 & 689 & 535 \\
\hline Accounts & 109 & 283 & 489 \\
\hline Active Users & 74 & 168 & 393 \\
\hline Tweets & 117,121 & 291,671 & 482,945 \\
\hline Followers & $2.3 \mathrm{M}$ & $0.5 \mathrm{M}$ & $32.7 \mathrm{M}$ \\
\hline Friends & 720,929 & 105,144 & $1,369,424$ \\
\hline
\end{tabular}

\subsubsection{Research Questions}

In this paper, we answer different questions regarding the social media behavior of politicians. Therefore, we have gathered data, as described. We use these to generate information out of the demographic data, like gender and age group. Furthermore, we compute analyses regarding the Twitter data like the numbers of tweets, followers and friends. Subsequently we use the language and environment $\mathrm{R}$ for statistical computing and graphics to analyse the data regarding our research topics (Gentleman and Ihaka, 2013).

In the next section we will present our findings. Afterwards we present in another section more analyses about social media on Twitter. In this part we show summary findings regarding our data set. 
Amongst others we have there analyses about the year of joining and a summary about the complete data set.

\section{FINDINGS}

This is one of two main parts of our studies, where we will present the results of our statistical calculations. Therefore, we extract relevant data for each analysis from our database and calculate figures regarding gender, age groups, tweets, followers, friends and the moving average and trend of tweets. Subsequently, we present our results in tables and figures.

\subsection{Gender}

In this subsection we want to find a relation between gender and the number of Twitter accounts among the parliamentarians. An exhaustive study of Twitter users across the world showed that more women $(53 \%)$ than men $(47 \%)$ are active on Twitter (Udani, 2012). Therefore, we assume a similar picture for politicians. In the following Figure 1 we present our findings. These figures show that in all parliaments the share of women with a Twitter account is larger then the share of men. We recognized that the number of male and female accounts in each country is close, but if we compare the countries we see significant differences, especially when compared with the U.S.

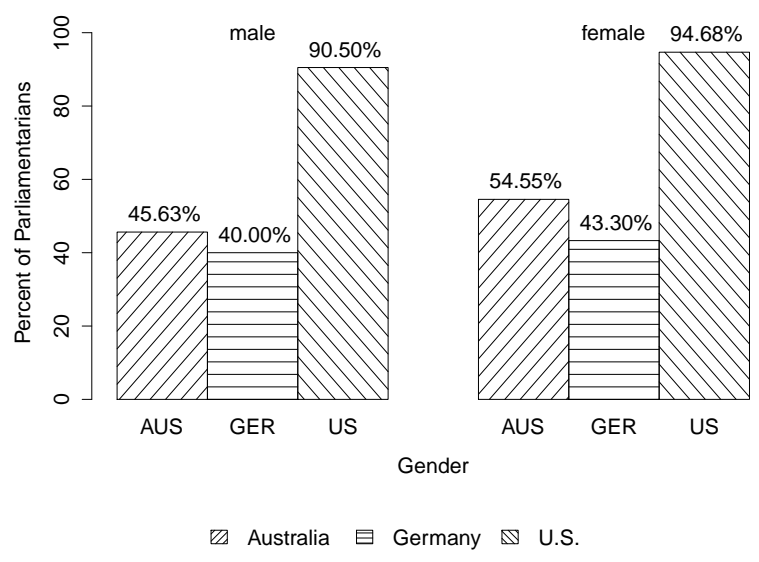

Figure 1: Accounts spread across gender.

For our statistical analysis regarding the gender we used the Pearson's Chi-squared test with Yates' continuity correction and got the results in Table 3 . Thereby following null hypothesis was accepted: Between men and women, there is no significant difference, regarding the number of Twitter accounts. If we put the $p$-values our significance level $\alpha=0.05$, we can see there is no significant $p$-value and therefore we can not reject our hypothesis. The Phi-coefficient in Table 3 shows us the strength of an relation. In our case we can see a relationship between gender and the number of accounts, but it is only a weak relation.

Table 3: Results for the statistical analysis regarding the gender and accounts.

\begin{tabular}{|l|r|r|c|}
\hline & Australia & Germany & U.S. \\
\hline $\mathrm{x}$-Squared & 1.1533 & 0.552 & 1.2129 \\
\hline $\mathrm{df}$ & 1 & 1 & 1 \\
\hline $\mathrm{p}$-Value & 0.2829 & 0.4575 & 0.2707 \\
\hline Phi-Coefficient & 0.08 & 0.03 & 0.06 \\
\hline
\end{tabular}

The second hypothesis we test for the gender is that the number of followers is related to the gender and the female politicians have more followers than male. So we use the t-test and compare the mean values of the male and female Twitter users of the individual parliaments. As null hypothesis, we assume that the mean values are equal. Our results in Table 4 show that there are no significant $\mathrm{p}$-values for our $\alpha=0.05$. Therefore, we must assume that there is no relation between the number of followers, and the gender.

Table 4: Results for the statistical analysis regarding the gender and followers.

\begin{tabular}{|l|r|r|r|}
\hline & Australia & Germany & \multicolumn{1}{c|}{ U.S. } \\
\hline Sum Men & 1823354 & 371768 & 31394863 \\
\hline Sum Women & 489467 & 179287 & 1279302 \\
\hline Mean Men & 24977 & 1998 & 78487 \\
\hline Mean Women & 13596 & 1848 & 14374 \\
\hline $\mathrm{t}$ & 0.6142 & 0.3135 & 1.0107 \\
\hline $\mathrm{df}$ & 102.87 & 200.447 & 402.011 \\
\hline $\mathrm{p}$-Value & 0.5405 & 0.7542 & 0.3127 \\
\hline Conf. Inter. & -25372 & -795 & -60586 \\
\hline Conf. Inter. & 48134 & 1096 & 188812 \\
\hline
\end{tabular}

\subsection{Age Groups}

In Figure 2 we can see an analysis of our data with respect to individual age groups. We expect that the younger generations are more represented on Twitter than the older ones, as younger generations adopt new technologies like Twitter faster than older. In addition to this outcome it also turns out, as already in the last section about gender, that far more politicians in the 
U.S. are present on Twitter. In comparison to Australia and Germany, this is particularly the case in the age groups over 35 years.

In Figure 2 we can see, while in the first age group $<34$ all three countries have an identical rate of $100 \%$. In Australia and Germany the rate declines in the following age groups. However, in the U.S. the rate always remains well above $80 \%$. In the U.S. Twitter plays a major role over all age groups, while the participation in Australia and Germany decreases with the age. With increasing age, this distance between the U.S. on the one hand and Australia and Germany on the other hand increases. This shows that there is a great catch-up in older politicians in the countries Australia and Germany.

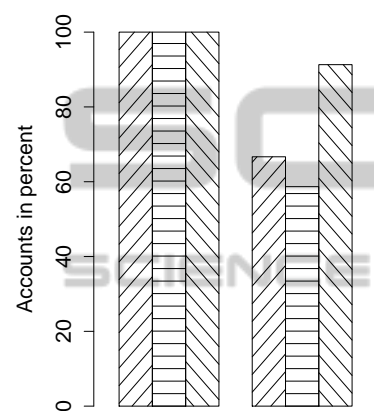

$<35$
$35-44$

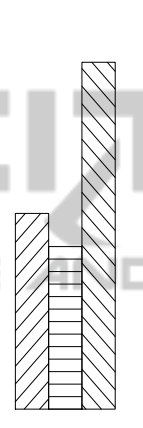

$45-54$

Age Groups

Z Australia 目 Germany $\mathbb{Q}$ U.S.

Figure 2: Accounts spread across age groups.

\subsection{Tweets \& Followers \& Friends}

In this section we compute the correlations for the variables tweets, followers and friends and present the results in scatter plots. A scatter plot displays the direction and strength of the linear relationship between two variables and therefore it is well suited.

First, we calculated the correlation and found a slight correlation of 0.16 between followers and tweets, even if our p-value indicates a statistically significant value, we can not assume at this low correlation that a politician can enlarge the number of his followers by publishing more tweets. We present the resulting scatter plot in Figure 3.

Second, as we have further assumed, there is a correlation between friends and followers. The Correlation Coefficient (cor) has a value 0.53 and it is thus worth to be classified as a medium correlation. This shows that politicians can increase their reach by adding more friends to their profile as this leads to an increase of followers.

Finally, we calculated the Correlation Coefficient (cor) for the variables friends and tweets. There we

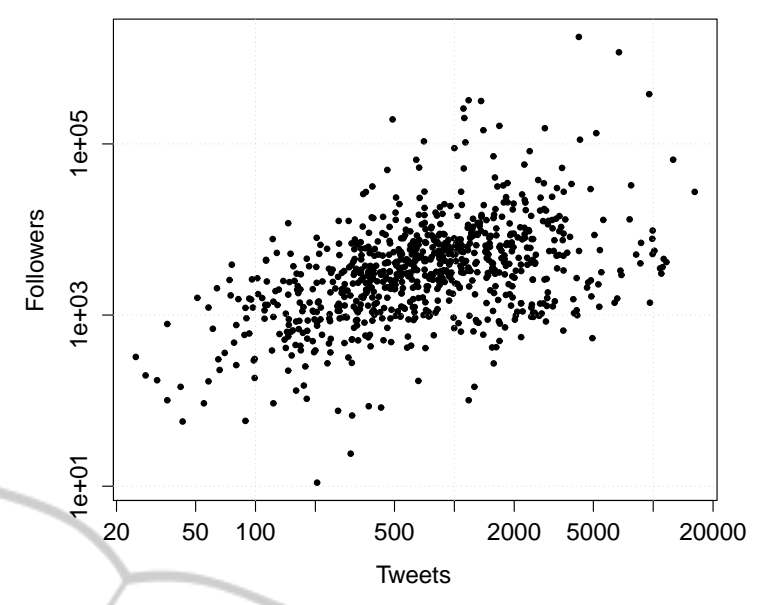

Figure 3: Correlation between followers and tweets. . can also find only a slight value of 0.14 . It reveals that the number of friends a politician has, is not related to the number of tweets and therefore a politician who tweets frequently does not necessarily add regularly friends to his network.

Our results in this section show, therefore, that politicians, especially when they actively invite friends in their network can achieve a greater scope. This is the case, as the addition of new friends increases the number of followers as we found through the calculation of the correlations.

\subsection{Tweets Moving Average and Trend}

In Figure 4 we show the simple moving average (SMA) and the trend for the U.S. parliament regarding the average of tweets. Thus we reveal, how the use of Twitter among parliamentarians has developed. The goal is to check whether a trend is present in the time series or not. For our calculations we used for each parliament the dates of the entire years from 2009 to 2012. The computations furthermore assume that the observations are independent. Since the gradients of the individual countries are comparable, we show only the U.S. figure as an example.

For Australia the figures show that for every turn of the year the SMA line has a deep, which means, that the politicians tweet less in this time. Nonetheless, we see a strong increase of the number of tweets during the investigated years from 2009 to 2012. At the end of the graph we see again that the number of tweets at year-end decreases in Australian parliament.

For the German figures we see the phenomenon for Australian turn of the year only from year 2009 to year 2010. Otherwise, the number of tweets increases during the relevant period. At the beginning less strongly but from mid-2011, we see a very strong 


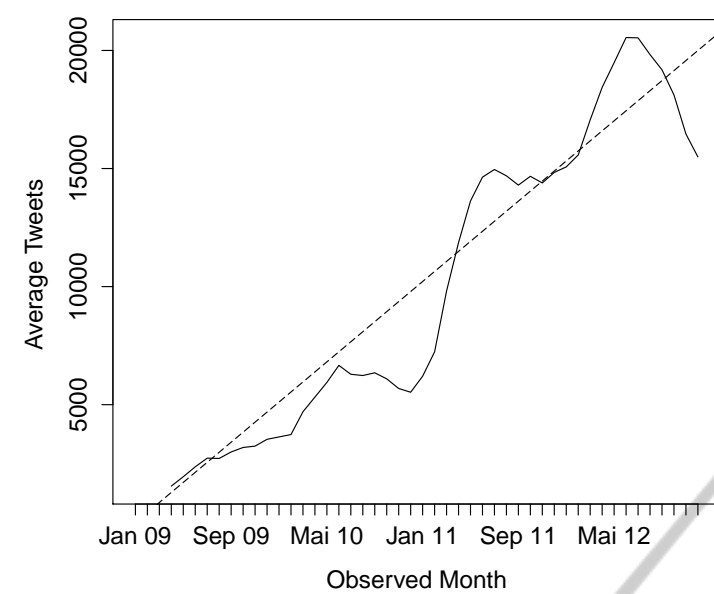

Figure 4: Moving average and trend for the number of tweets in the U.S.

increase, which only will weaken slightly at the end of the year 2012 .

Finally, we have the SMA and trend for the number of tweets in the U.S. in Figure 4. Here we can see again at the turn of the years $10 / 11$ and $11 / 12$ there is a decrease in the number of tweets. In the U.S. there is a strong increase in the number of tweets in the same period. However, in 2012 the number of tweets has fallen steadily since mid-year, what can be observed in the corresponding period at the slope of the graph.

\section{SUMMARY FINDINGS}

This is the second part of our findings, where we present summary results. In addition to examination of our entire data set we investigate the year of joining and trending topics.

\subsection{Data Summary}

In this subsection we show some descriptive analyses for our complete data set. Therefore, we present for each parliament the classical five-number summary (sample minimum, first quartile, median, third quartile, sample maximum) together with the mean and standard deviation $(\sigma)$, which are normally no part of the five-number summary. These figures are used because they provide a concise summary of the distribution and also point out the center and spread of it. This makes it possible to compare quickly the resulting numbers of our observations.

Table 5 shows the summary regarding the number of tweets. At minimum we can recognize that in each parliament there are politicians, which have a Twitter account but never posted a tweet. Furthermore for
Germany we can see the largest mean and 3rd quartile, which leads to the conclusion that Germany has compared to the other countries the most active quarter of politicians on Twitter. The standard deviation shows in the U.S., the number of tweets seen from the parliament deviates the least from the mean values.

Table 5: Summary statistics regarding tweets.

\begin{tabular}{|l|r|r|r|}
\hline & Australia & Germany & U.S. \\
\hline Minimum & 0 & 0 & 0 \\
\hline 1st Quartile & 218 & 146 & 369 \\
\hline Median & 576 & 440 & 694 \\
\hline Mean & 1,348 & 1,390 & 1,060 \\
\hline 3rd Quartile & 1,631 & 1,728 & 1,289 \\
\hline Maximum & 11,620 & 16,650 & 12,900 \\
\hline Stand. Dev. & 2,048 & 2,303 & 1,309 \\
\hline
\end{tabular}

Now we look at the following summary in Table 6. Germany compared to Australia and the U.S. has by far the lowest follower numbers. However, the U.S. has by far the biggest follower numbers. Based on the mean values it is well to assess in which category the individual countries are classified.

Table 6: Summary statistics regarding followers.

\begin{tabular}{|l|r|r|r|}
\hline & Australia & Germany & \multicolumn{1}{c|}{ U.S. } \\
\hline Minimum & 57 & 0 & 0 \\
\hline 1st Quartile & 1,491 & 457 & 2,518 \\
\hline Median & 3,201 & 977 & 4,664 \\
\hline Mean & 21,220 & 1,947 & 66,820 \\
\hline 3rd Quartile & 6,274 & 1,656 & 8,185 \\
\hline Maximum & 1.2 Mio. & 32,440 & 25.3 Mio. \\
\hline Stand. Dev. & 117,388 & 3,865 & $1,145,331$ \\
\hline
\end{tabular}

Table 7 shows a similar picture for the friends as we have already seen in the followers. Germany has by far the lowest and U.S. by far the most friends. Australia is again between the two countries. This suggests that there is a dependence between the followers and friends. This conjecture, we already examined in more detail with our statistical findings in the section about the correlations between tweets and followers and friends. 
Table 7: Summary statistics regarding friends.

\begin{tabular}{|l|r|r|r|}
\hline & Australia & Germany & U.S. \\
\hline Minimum & 0 & 0 & 0 \\
\hline 1st Quartile & 159 & 55 & 123 \\
\hline Median & 442 & 146 & 359 \\
\hline Mean & 6,614 & 371 & 2,800 \\
\hline 3rd Quartile & 986 & 359 & 1,114 \\
\hline Maximum & 369,800 & 12,560 & 667,800 \\
\hline Stand. Dev. & 40,258 & 909 & 30,329 \\
\hline
\end{tabular}

\subsection{Year of Joining}

From Cheng et al. we know that the big hype of Twitter was in 2009 (Cheng et al., 2009). We assume that this also applies for politicians, and compared to other years, most of the investigated politicians have their Twitter account created in 2009 . We will check this to see whether the number of politicians in the year 2009 actually is the highest, or whether the number is maybe bigger in an election year. To determine how the proliferation of Twitter has evolved in the political landscape over the years, we have analysed the data collected to that effect.

Twitter was launched in 2006 and the first politician of the current parliaments have created their accounts in 2007. In Australia and Germany this was one politician in each country, whereas in the U.S. 14 politicians created their Twitter account in 2007.

In Figure 5 we can see that in the U.S. 2009 was the peak of the Twitter hype. Also we can see in our data that, although in this year in Germany was the Federal Election, the percentage of new arrivals in both countries are almost on par with $23.45 \%$ in Australia and $23.06 \%$ in Germany. In the U.S. the share with $33.83 \%$ is even bigger.

If we look at the already shown figures in a cumulative shape, we can see that the number of Twitter joining politicians is the highest in the U.S. over all three years. Our data set also shows that, altogether the share of politicians with a Twitter account in Australia with $48.23 \%$ is higher than in Germany with $41.07 \%$. Nevertheless the largest share of Twitter accounts in the parliament has the U.S. with $91.40 \%$. Such a high percentage of politicians with a Twitter account in the U.S. shows that social media is accepted as a medium for sharing political information in this country. In Australia and Germany, this is not seen to such an extent. In Figure 6 we show the figures for the U.S. as an example.

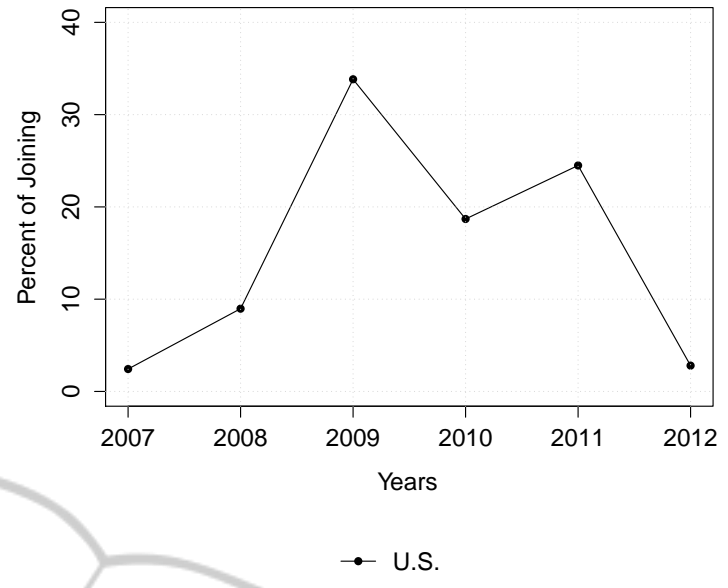

Figure 5: Year of joining per cent.

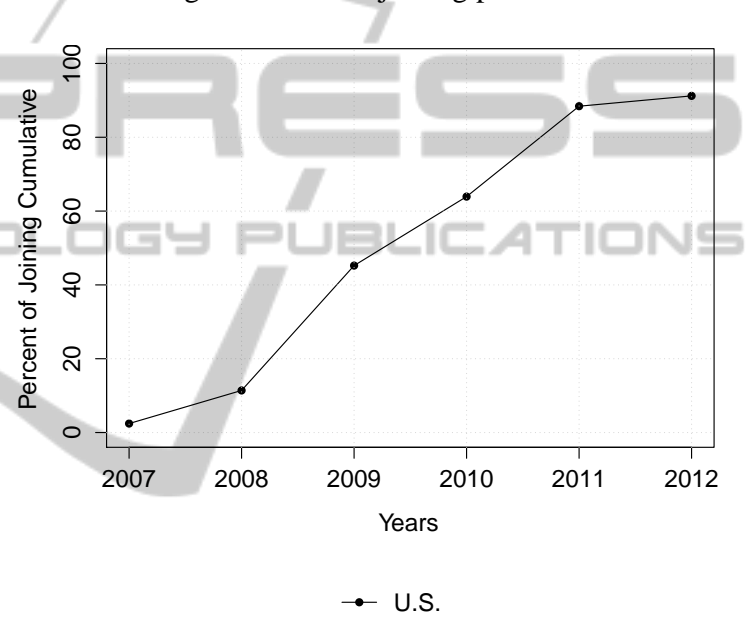

Figure 6: Year of joining cumulative.

\subsection{Trending Topics}

In addition to the previously described indicators of our data set, we have also examined the trending topics in each parliament during the year 2012. Here we have analysed all the tweets from our possession in 2012.

After we excluded filler words, like is, the and others, we took the three mostly mentioned words for each country. They are ordered by their frequency for

- Australia

1. Carbon tax

2. Health

3. Economy

- Germany

1. Europa

2. Fiskalpakt

3. Griechenland 
- U.S.

1. Job

2. Tax

3. Health

Then we have considered the individual tweets to the respective topics in more detail in order to get an idea for what the discussion was.

\subsubsection{Australian Trending Topics}

As already mentioned the most trending topics in Australia were the carbon tax, health and furthermore the economy. When we look at the line of carbon tax in Figure 7, we see a rise in the mid of the year 2012, with a peak in July. This we can justify by the fact, that the carbon pricing scheme for business was introduced in Australia by the Gillard government at the 1st July 2012. During the text analysis of single tweets with respect to the keyword health, we found that in this context also often the following keywords are used: Denticare, Medicare and Private Health Insurance.

Our data set shows a continuous discussion on these different health topics. Regarding the economic topic we can give two different reasons for the ongoing discussion. For one thing, Moody's have reaffirmed in May the AAA credit rating of Australia, due to a strong economy and strong public finances. Therefore, we see an increase in May and June for the economic topic. On the other hand in the parliament was regularly praised the low unemployment rate, low inflation, low interest rates and the economy growing trend.

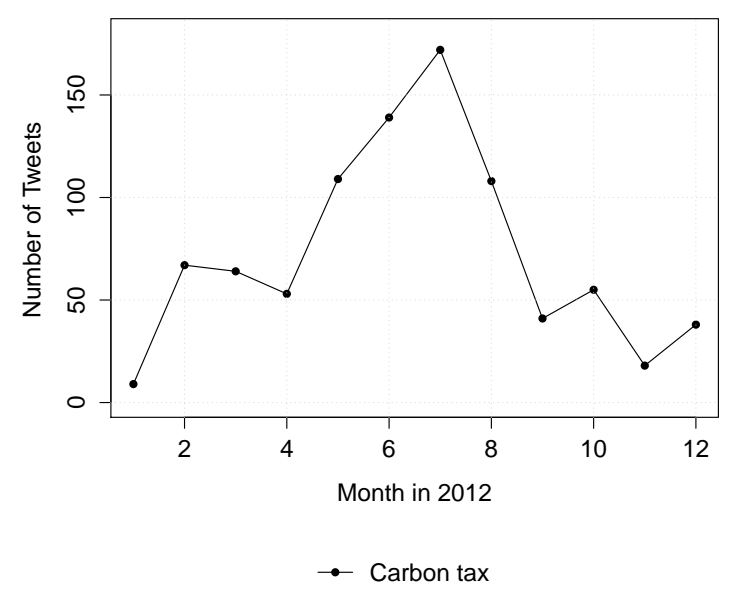

Figure 7: Trending topics in Australia.

\subsubsection{German Trending Topics}

The most mentions of the German parliament in 2012 had the topic Europe (German: "Europa") as we can see in Figure 8. Followed by the topics European Fiscal Compact (German: "Fiskalpakt") and Greece (German: "Griechenland"). For the keyword Europe the peak in June and the previous rise was created by a lively discussion about the Euro Crisis, the Europe politics and the commercial policy altogether. Also we can see a rise in September and October. The reason for that is the award of Nobel Peace Prize to the European Union.

The European Fiscal Compact sets for the European countries a debt limit in relation to the Gross Domestic Product (GDP). Furthermore this compact sets an upper limit for the annual new debt also in relation to the GDP and establishes penalties for noncompliance with these two limits. In Germany, the compact on 29th June 2012 entered into force, which leads to the peak in June. The last we have seen of Germany was the catchphrase Greece.

Here we see two rises. One in February and another in November of 2012. This is the case, as was voted in these two months each on a bail-out package for Greece in the German parliament. In February was voted for the bail-out package number two and in November for number three.

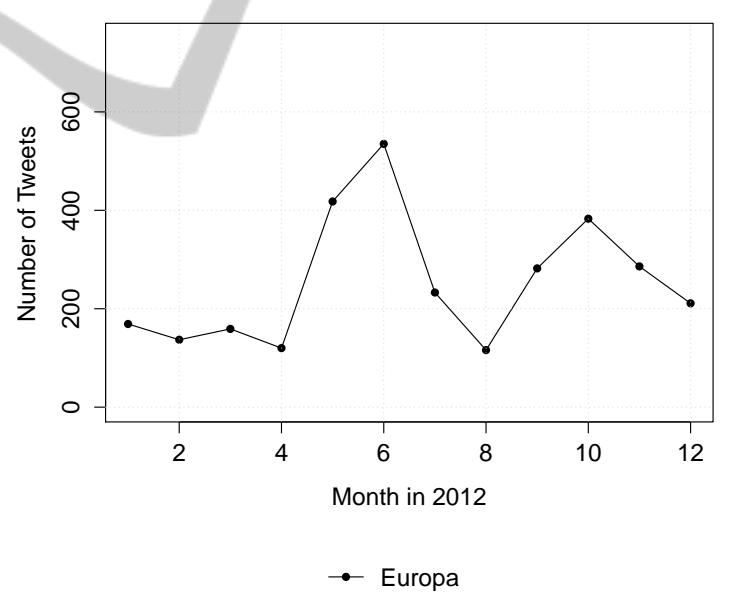

Figure 8: Trending topics in Germany.

\subsubsection{American Trending Topics}

Australia and Germany have shown that the trending topics especially in the middle of the year reach maximum values. But for the U.S. we can see in Figure 9 the mostly mentioned topic about jobs has already in March the highest value. But also in June and July the topic reaches high values. According to our data the reason for that are good job growth figures which are published in these months. The mentions of the tax topic are high, as regularly about the achievements of Obama tax cuts. 


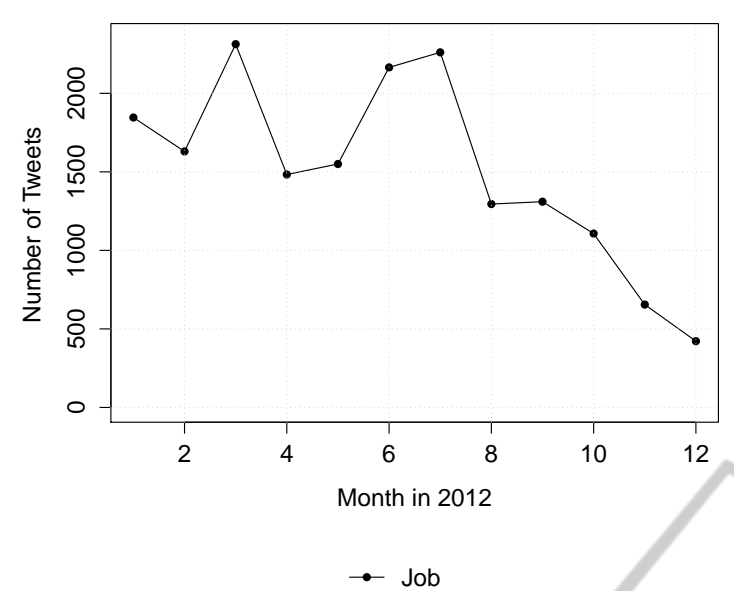

Figure 9: Trending topics in the U.S.

Also frequently was discussed about the tax plans of Obama and Romney after the 2012 elections. The last U.S. topic is health, and here especially the Patient Protection and Affordable Care Act (PPACA) which is commonly called Obamacare or the Federal Health Care Law. It was signed into law by President Barack Obama on 23rd Mach 2010, but PPACA contains provisions that became effective after enactment and therefore there is still a regular discussion about this topic in the U.S. parliament.

Overall we have seen for Australia and the U.S. that the three most important issues are about economic (jobs, taxes) and health topics. For Germany, however, we see that the three main topics revolve mainly around Europe.

\section{CONCLUSIONS AND FUTURE WORK}

This paper focuses on social media in politics and therefore especially on the Twitter platform and the parliaments of Australia, Germany and the U.S. Firstly, this paper provides an introduction to the topic of social media in politics including Twitter followed by other related work. Secondly, we describe the used methodology for our studies with data collection and our research questions. Then we provide the key findings of our investigations, based on statistical results. Here we found that the investigated politicians in each country showed a growing interest in social media. This we were able to see, because of the growing number of Twitter accounts registered by the politicians and also by the increasing number of tweets posted by the politicians. We have also found that politicians use Twitter not only for political campaigns but also for daily political discussions. Still we have learned much about trending topics in parliaments. About which topics were most discussed in the parliaments and also about the lifetime of topics in the investigated parliaments.

Regarding the topic of social media in politics the contributions of this paper are as follows. Overall we provide insight into the topic of social media in politics with a focus on Twitter. We did not focus only on the U.S. as in previous studies, but always conducted the comparison with Australia and Germany. Next to an insight into the subject, the results also provide suggestions for dealing with social media in the political context.

Our results provide an insight into social media in politics with Twitter, but it will be important in future research to address more social media platforms. Especially the frequently used platforms in politics of Facebook and YouTube should be investigated in more detail. Furthermore, the individual websites or blogs of politicians could be investigated or even traditional media like newspapers, magazines and TV channels. This would provide a more detailed picture of this topic. Also other countries could be added to obtain more comprehensive results.

\section{REFERENCES}

Adler, Gent, O. (1998). The home style hompage: Legislator use of the world wide web for constituency contact. Legislative Studies Quarterly, 23:585-595.

Alexa (2012). Alexa - The Web Information Company. http://www.alexa.com/.

Backstrom, L., Huttenlocher, D., Kleinberg, J., and Lan, $X$. (2006). Group formation in large social networks: membership, growth, and evolution. In Proceedings of the 12th ACM SIGKDD international conference on Knowledge discovery and data mining, KDD '06, pages 44-54, New York, NY, USA. ACM.

Cheng, A., Evans, M., and Singh, H. (2009). Inside Twitter: An in-depth look inside the Twitter world.

Esterling, K., Lazer, D., and Neblo, M. (2005). Home (page) style: House members on the web. In DG.O.

Facebook (2012). Facebook - Key Facts. http:// newsroom.fb.com/content/default.aspx.

Gentleman, R. and Ihaka, R. (2013). The R project for statistical computing. http://www.r-project.org/.

Golbeck, J., Grimes, J. M., and Rogers, A. (2010). Twitter use by the U.S. Congress. J. Am. Soc. Inf. Sci. Technol., 61(8):1612-1621.

Java, A., Song, X., Finin, T., and Tseng, B. (2007). Why we twitter: Understanding microblogging usage and communities. In Proceedings of the 9th WebKDD and 1st SNA-KDD 2007 workshop on Web mining and social network analysis, WebKDD/SNA-KDD '07, pages 56-65, New York, NY, USA. ACM. 
Missingham, R. (2010). The Australian parliament in the Twitterverse.

Morphy, E. (2012). Twitter to reach 500M registered users on Wednesday. Just another day in the life of the social media fun house. http://www.forbes.com/sites/ erikamorphy/2012/02/21/twitter-to-reach-500mregistered-users-on-wednesday-just-another-day-inthe-life-of-the-social-media-fun-housel.

Semiocast (2012). Twitter reaches half a billion accounts - More than 140 millions in the U.S. http:// semiocast.com/publications/2012_07_30_Twitter _reaches_half_a_billion_accounts_140m_in_the_US.

Smith, K. N. (2011). Social Media and Political Campaigns.

Tumasjan, A., Sprenger, T. O., Sandner, P. G., and Welpe,

I. M. (2010). Predicting elections with Twitter: What 140 characters reveal about political sentiment. In Proceedings of the Fourth International AAAI Conference on Weblogs and Social Media, pages 178-185.

Twitter (2012). Twitter API Documentation. https:// dev.twitter.com/.

Udani, G. (2012). An exhaustive study of Twitter users across the world. http://www.beevolve.com/ twitter-statistics/.

Wasserman, S. and Faust, K. (1994). Social Network Analy sis: Methods and Applications. Cambridge University Press. 